\section{BLOG EDUCACIONAL E O ENSINO DAS DANÇAS FOLCLÓRICAS NAS AULAS DE EDUCAÇÃO FÍSICA: APROXIMAÇÕES A PARTIR DO CURRÍCULO DO ESTADO DE SÃO PAULO}

\author{
EDUCATIONAL BLOG AND THE TEACHING OF FOLK DANCES IN PHYSICAL \\ EDUCATION CLASSES: APPROACHES FROM THE SÃO PAULO STATE \\ CURRICULUM
}

\author{
BLOG EDUCATIVO Y LA ENSEÑANZA DE DANZAS FOLCLÓRICAS \\ EN EDUCACIÓN FÍSICA: ENFOQUES DEL CURRÍCULO ESTADO DE \\ SÃO PAULO
}

\author{
Irlla Karla dos Santos Diniz*, Suraya Cristina Darido**
}

\section{Palavras-chave} Educação Física. Dança.

Blog.

Currículo.

\section{Keywords:}

Physical Education.

Dance.

Blog.

Curriculum.
Resumo: 0 objetivo deste estudo foi elaborar e avaliar um material didático complementar ao currículo de Educação Física do Estado de São Paulo sob a forma de blog educacional de danças folclóricas. Desenvolveu-se uma pesquisa qualitativa organizada em três etapas: análise documental do currículo em relação à dança, produção do blog e avaliação por professores. O blog foi apontado como ferramenta de formação continuada possibilitando acesso rápido e reunião de diversas mídias em um mesmo espaço virtual. Contudo, identificaram-se limitações no emprego dessa ferramenta com relação à organização dos conhecimentos da dança, à estrutura escolar e às condições do trabalho docente.

Abstract: The aim of this study was to develop and evaluate supplementary teaching materials to the curriculum of Physical Education of the State of São Paulo in the form of educational blog of folk dances. A qualitative survey was conducted in three steps: documentary analysis of curriculum in relation to dance, blog production, and evaluation by teachers. The blog was indicated as a continuing training tool enabling quick access and gathering various media in the same virtual space. However, limitations were identified in the use of this tool for the organization of dance knowledge, the school structure and the conditions of teaching.

Resumen: El objetivo del estudio fue desarrollar y evaluar un material didáctico complementario al currículo de Educación Física del Estado de São Paulo, en la forma de un blog educativo de danzas folclóricas. Fue desarrollado un estudio cualitativo en tres pasos: análisis documental en el currículo en relación a la danza; la producción del blog y evaluación por los profesores. El blog fue designado como herramienta de formación continua que permite un acceso rápido y el cumplimiento de diversos medios de comunicación en el mismo espacio virtual. Sin embargo, se identificaron las limitaciones en el uso de esta herramienta para la organización del conocimiento en la danza; la estructura de la escuela y las condiciones de enseñanza.
*Instituto Federal de Educação, Ciência e Tecnologia de São Paulo, Capivari, SP, Brasil.

Email: irllakarla@yahoo.com.br

** Universidade Estadual Paulista "Júlio de Mesquita Filho". Rio Claro, SP, Brasil.

E-mail: surayacd@rc.unesp.br

Recebido em: 27-01-2015

Aprovado em: 06-06-2015 


\section{INTRODUÇÃO'}

A dança é compreendida como uma prática corporal tradicional realizada desde os povos primitivos até os contemporâneos (EHRENBERG, 2003). Ela foi transformada e ressignificada ao longo da história da humanidade acumulando múltiplos sentidos, sendo influenciada por elementos culturais, religiosos e sociais. Pode-se dizer que dança envolve, dentre outras características, os movimentos ritmados, a técnica, a estética, a expressividade e a relação existente entre os passos.

A análise desses fatores permite compreender essa manifestação como um dos componentes da cultura corporal, o que levou, principalmente após o processo de escolarização, a sua identificação como um dos conteúdos da Educação Física. Entende-se que esse componente curricular apresenta como premissa introduzir e integrar o aluno na esfera da cultura corporal, instrumentalizando-o para usufruir das práticas corporais como um conhecimento para a vida em sociedade (DARIDO; SOUZA JÚNIOR, 2007).

A dança, neste contexto, assume um papel importante como uma destas manifestações corporais, todavia, sabe-se que diversas limitações interferem em sua inserção na escola (MARQUES, 1997; BRASILEIRO, 2002; KLEINUBING; SARAIVA, 2009). Fatores como a dificuldade dos professores em tratá-la devido à falta de experiências com este conteúdo em diferentes espaços sejam eles educativos ou não, as condições estruturais da escola, a desvalorização da própria área de Educação Física que não propõe de maneira efetiva que a dança abordada nos currículos de formação inicial, se configuram em alguns exemplos.

Além dessas razões, o preconceito e a falta de credibilidade de tal prática corporal perante os alunos, elemento fortalecido pela cultura esportivista das aulas dessa disciplina, podem ser considerados como agravantes desse cenário. Nesse escopo, entende-se que as possibilidades pedagógicas para abordar a dança são minimizadas e frequentemente ignoradas no campo escolar.

Desenvolvendo um contraponto, pode-se dizer que a dança possui uma tradição reconhecida no contexto escolar que pode ser interpretada como contraditória, uma vez que, apesar do distanciamento no que se conjectura com o contexto pedagógico da disciplina de Educação Física, ela aparece de forma premente nos eventos escolares, como festas temáticas, por exemplo.

Compreende-se, portanto, que o espaço ocupado pela dança necessita ser ampliado e ressignificado, ofertando aos alunos experiências pedagógicas concretas e sistemáticas que lhes permitam usufruir desse conteúdo como um conhecimento significativo no exercício da cidadania.

Isso posto, aponta-se que o currículo enquanto um dos orientadores da prática pedagógica (SACRISTÁN, 2000) torna-se um referencial importante na proposição e efetivação de mudanças relevantes na maneira como os conteúdos são ensinados na escola. Portanto, o currículo se concretiza como um elemento que merece uma investigação mais cuidadosa.

O currículo de Educação Física do Estado de São Paulo (SÃO PAULO, 2011) foco deste estudo, apresenta uma sistematização dos conteúdos orientando como os conhecimentos deveriam ser tratados ao longo dos anos escolares por meio de dois materiais distintos, 0 caderno do professor e o caderno do aluno.

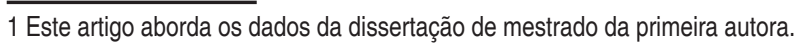


Os objetivos propostos para tratar a dança no currículo estão baseados em uma perspectiva multicultural, por meio da exploração de danças folclóricas características de cada uma das regiões do país. Neste escopo, são propostas no caderno do professor: 0 xaxado (Região Nordeste); o carimbó (Região Norte); o siriri (Região Centro-Oeste); a catira (Região Sudeste); e a chula (Região Sul), como manifestações que deveriam ser tematizadas nas aulas de Educação Física. Contudo, a proposta parece limitada, uma vez que os conhecimentos e sugestões sobre essa temática são apresentados de forma resumida.

O ensino das danças folclóricas é um grande desafio devido sua diversidade de manifestações e conhecimentos envolvidos, além do intenso significado cultural dessas práticas em cada contexto de origem. Como assevera Toledo (2011) as danças folclóricas manifestam de forma expressiva e estética a cultura de um povo, proporcionando uma identificação da região de origem, devido os elementos que as caracterizam, como a história, lendas e costumes.

Seria importante refletir sobre algumas possibilidades pedagógicas que pudessem contribuir com a ação do professor acerca do processo de ensino e aprendizagem do conteúdo de danças folclóricas.

Considerando o contexto social, uma alternativa interessante seria favorecer a formação de docentes por meio do uso das Tecnologias da Informação e da Comunicação (TIC), devido seu amplo desenvolvimento nos últimos anos, bem como, diversas possibilidades de ação no campo educacional (MASETTO, 2006). Como aponta Scherer (2005) a formação e a educação estão alcançando novas possibilidades com o desenvolvimento das tecnologias.

Dentre as variadas ferramentas existentes, o blog se apresenta como uma alternativa interessante devido ao espaço que vem galgando nos últimos anos (FRANCO, 2005; MARQUES; MÜLLER, 2012). Características como o fácil acesso e manipulação, fonte de conhecimento e entretenimento e propostas educativas, têm sido apontadas como responsáveis pela popularização desta plataforma.

A partir desses delineamentos, o objetivo do presente estudo foi elaborar e avaliar um material didático complementar ao currículo de Educação Física do Estado de São Paulo, sob a forma de um blog educacional, para subsidiar a atuação pedagógica do professor no conteúdo de danças folclóricas proposto para o sétimo ano do ensino fundamental.

\section{MÉTODO}

Esta é uma investigação qualitativa que foi desenvolvida em três etapas distintas. Devido suas especificidades, a pesquisa foi encaminhada ao Comitê de Ética em Pesquisa (CEP-IB-UNESP), sendo aprovado com número de registro 7411. Além disso, todos os participantes preencheram o Termo de Consentimento Livre e Esclarecido (TCLE), possuindo responsabilidades e direitos oficializados neste documento.

\subsection{Primeira Etapa}

Foi realizada inicialmente uma análise documental (GIL, 2008) sobre o conteúdo de dança apresentado pelo currículo de Educação Física do Estado de São Paulo (caderno do professor), presente no sétimo ano do ensino fundamental, para subsidiar a produção do blog 
educacional. Este nível de ensino foi selecionado, visto que, de acordo com a sistematização dos conteúdos proposta pelo currículo, o sétimo ano é o primeiro momento em que a dança é sugerida.

Foram analisados os textos, atividades, imagens e demais sugestões presentes, a fim de identificar quais as possibilidades e limitações do currículo, procurando delinear um plano de ação para a construção do material didático complementar idealizado na pesquisa.

\subsection{Segunda Etapa}

Este momento caracterizou-se pela elaboração do material didático que alimentou o blog educacional ${ }^{2}$ de danças folclóricas. Desta forma, a plataforma foi produzida procurando complementar o conteúdo apontado para as cinco manifestações presentes no caderno do professor (catira, chula, siriri, xaxado e carimbó), e aprofundar as propostas de ensino e aprendizagem.

O blog foi selecionado como plataforma digital devido sua ausência de custos, facilidade de elaboração e manipulação, bem como, sua dinamicidade e velocidade na disponibilização das informações.

\subsection{Terceira Etapa}

$\mathrm{Na}$ última etapa foi realizada a avaliação do blog. Este processo foi efetivado por meio de entrevistas semiestruturadas (LÜDKE; ANDRÉ, 1986) com seis professores da área de forma individualizada. Para selecionar os participantes foram direcionadas cartas-convite para algumas escolas estaduais que atestaram a utilização do currículo de Educação Física do Estado de São Paulo. 0 estudo foi desenvolvido em um município de médio porte do interior do estado, local de desenvolvimento da pesquisa de mestrado da primeira autora.

Como critérios de seleção de participantes foram utilizados os seguintes pontos: o professor deveria trabalhar com o currículo e com o sétimo ano do Ensino Fundamental; possuir interesse em avaliar o material proposto; e contribuir com a versão final do blog educacional de danças folclóricas.

A partir deste contato inicial e dos critérios de seleção, seis professores de três escolas distintas concordaram em participar do estudo. $O$ grupo foi formado por três homens e três mulheres com média de idade de 48,83 anos, e apenas dois apresentavam experiências prévias com 0 conteúdo de dança na escola.

Depois que os participantes foram selecionados, realizou-se a primeira entrevista semiestruturada (LÜDKE; ANDRÉ, 1986). Neste momento, foi construído um diagnóstico inicial sobre as principais dificuldades com relação à dança e as tecnologias. Num segundo momento, foram realizadas as visitas orientadas ao blog educacional, em que todos os docentes participaram. Posteriormente os docentes foram convidados a desenvolver aulas de danças folclóricas na escola a partir do material sugerido no blog, todavia, apenas dois aceitaram participar dessa etapa de implementação. Ao todo foram três aulas em uma escola e duas na outra, com 50 minutos cada uma. Essas experiências foram observadas pelas pesquisadoras e registradas por meio de diário de campo, fotos e vídeos.

2 Link do blog educacional de danças folclóricas produzido nessa pesquisa está disponível em: <http://dancanaefe.blogspot.com.br/> 
Por fim, essa fase foi encerrada com uma entrevista semiestruturada, em que todos participantes foram questionados diretamente sobre as possibilidades e limites do blog educacional de danças folclóricas.

Para fins de análise dos dados foi desenvolvida uma análise qualitativa descritiva na primeira e segunda etapa da pesquisa. Já para a terceira foi empregada a análise de conteúdo (BARDIN, 2011), aplicando o que autora denomina de categorização temática.

\section{ANÁLISE E DISCUSSÃO}

\subsection{Análise do currículo de Educação Física do Estado de São Paulo}

O currículo de Educação Física do estado de São Paulo aponta em suas diretrizes que pretende proporcionar um subsídio básico para que o professor possa desenvolver os conteúdos propostos para cada nível de ensino, por meio da diversificação, sistematização e aprofundamento dos conteúdos (SÃO PAULO, 2009).

Todavia, ao longo do caderno do professor percebem-se algumas limitações nas propostas, considerando que os conhecimentos acerca das danças folclóricas são sucintos. Esse dado corrobora com o apontado por Neira (2011), uma vez que o autor ao analisar o currículo de Educação Física do estado de São Paulo, afirma que os temas são apresentados de forma resumida, oferecendo pouco suporte ao professor.

A dança é desenvolvida no currículo dentro do eixo de conteúdos "atividades rítmicas". No entanto, para o documento este tema "atravessa" os demais, visto que o ritmo é compreendido em sua etimologia original, possuindo relação direta com a organização temporal. Desta forma, a dança se constitui apenas em uma parcela dos conteúdos que devem ser explorados neste eixo.

A proposta explicitada no caderno do professor é que esta prática corporal seja empregada por meio da diversificação de ritmos, incluindo as danças folclóricas que caracterizam a cultura regional brasileira. O material não especifica qual foi o critério adotado na escolha das manifestações abordadas, nem o motivo pelo qual o sétimo ano foi selecionado como o primeiro espaço deste conteúdo no ensino fundamental.

Estes fatores indicam que na ausência de um currículo mínimo para a Educação Física no país, que oferte orientações às demais propostas curriculares que são construídas, o critério adotado para sistematização acabou sendo de ordem pessoal dos autores. Diversos pesquisadores da área (KUNZ, 1991; FREIRE; SCAGLIA, 2004; GONZÁLEZ, 2006) discorrem sobre a questão curricular na Educação Física, considerando este problema como uma das causas que levam à falta de status da disciplina, bem como de falta de legitimidade frente aos demais componentes curriculares. Esse contexto salienta a dificuldade de propor e elaborar uma proposta curricular, tendo em vista que a área, ainda não apresenta total concordância sobre o tema.

O enfoque atribuído à dança no caderno do sétimo ano parte de uma perspectiva multicultural, explorando a diversidade rítmica do Brasil por meio de manifestações folclóricas e tradicionais (catira, xaxado, chula, carimbó e siriri). Esse fato pode ser constatado, uma vez 
que, o material propõe que o aluno conheça a diversidade de manifestações rítmicas brasileiras, bem como, o processo histórico envolvido em sua formação e transformação social. Ademais, é reforçada ao longo do texto, a importância de valorizar e não manifestar preconceitos em relação a essas práticas, como é possível observar em alguns trechos:

É importante, durante o processo, que os alunos sejam capazes de compreender a riqueza de manifestações rítmicas de seu país e de seu Estado. [...] perceber, compreender e valorizar de maneira não preconceituosa e discriminatória as características das diferentes manifestações rítmicas nacionais e regionais (SÃO PAULO, 2009, p. 27-30).

Todavia, apesar de se tratar de uma proposta interessante do ponto de vista pedagógico, o material pode ser considerado sucinto ${ }^{3}$, principalmente no que se refere ao suporte teórico apresentado aos docentes para tratarem as danças folclóricas. Isso pode ser verificado, tendo em vista que foi oferecido apenas um quadro resumo, com informações acerca das manifestações previstas para o bimestre. Ou seja, os principais conhecimentos dessas manifestações, que deveriam versar sobre as características de cada dança, a formação histórico-cultural, bem como, os passos básicos, não parecem suficientes para subsidiar o desenvolvimento das aulas, ainda mais para aqueles professores que possuem pouco embasamento prévio sobre o tema.

Segue um exemplo do que é apresentado acerca de uma das manifestações sugeridas pelo material: "Chula (região Sul) - Muito popular no Rio Grande do Sul, essa dança masculina de movimentos vigorosos assemelha-se ao sapateado, cuja disputa se dá entre dois dançarinos" (SÃO PAULO, 2009, p. 29). Como é possível observar, são poucos conhecimentos oferecidos ao docente.

Evidente que um professor com boas condições de formação inicial e continuada, ou ainda com experiências relacionadas a estas temáticas, pode tratar as danças folclóricas com ou sem material, no entanto, entende-se que para muitos docentes esse apoio seria fundamental. Portanto, foi a partir dessa constatação na primeira etapa da pesquisa que se buscou avançar no material didático que seria produzido.

\subsection{Elaboração do Blog}

Após o levantamento realizado com a análise documental e identificação de algumas limitações do currículo, iniciou-se a elaboração do material didático que foi publicado no blog educacional de danças folclóricas.

A plataforma do blog foi documentada por meio de uma licença Creative Commons (CC) tornando-se um Recurso Educacional Aberto (REA)4. Essa licença permite que os usuários façam downloads dos materiais desde que o autor receba os créditos pela produção.

Cada manifestação presente no blog (xaxado, carimbó, siriri, catira e chula) foi organizada em tópicos/temas para facilitar aos participantes a localização das informações. Pela falta de embasamento na literatura que apoiasse essa seleção foram elencados pontos entendidos como necessários aos professores para ensinarem estas manifestações, bem como, que fossem interessantes para os alunos aprenderem.

30 conteúdo base que traz os conhecimentos e informações sobre cada uma das danças folclóricas propostas é apresentado em um quadroresumo que ocupa apenas uma folha do caderno do professor.

4 Maiores informações sobre o tema no site <http://rea.net.br/site/>. Acesso em 22 dez. 2013. 
Neste escopo, foram propostos: a "Origem", em que foram tratados elementos gerais sobre surgimento de cada manifestação; "Dança e passos", tópico em que foram explorados alguns passos básicos e possibilidades coreográficas; "Música e letras", constando uma breve descrição de como são as músicas e algumas letras; "Vestimentas", caracterizando elementos relacionados às roupas utilizadas durante a realização das danças; "Como é atualmente", analisando o contexto da manifestação na atualidade; "Sugestões de atividades", que reunia algumas propostas didáticas para os professores utilizarem em suas aulas; e por fim, "Sugestões de Vídeos", que apresentavam alguns materiais audiovisuais.

\subsection{Categorias de Análise}

\subsubsection{Possibilidades didático-pedagógicas do estudo}

\subsubsection{Facilidade de acesso e organização da informação}

Os seis professores participantes conceberam o blog de danças folclóricas como uma ferramenta interessante do ponto de vista formativo, principalmente pela oportunidade de explorar conhecimentos acerca dos conteúdos mais fragilizados na Educação Física escolar, como é o caso da dança.

O blog é muito interessante... muito assim... que dá para ser utilizado em aula, pois é uma coisa bem dinâmica, é uma coisa para se usar em sala de aula, e não é só para você, é para os alunos também [...]. (Professor 4).

Um estudo desenvolvido por Silva (2012) também apontou, a partir da perspectiva de professores, o blog como uma ferramenta didática interessante para a Educação Física, voltado, no entanto, para o ensino da capoeira. Os blogs também já foram explorados em outras áreas de conhecimento, tanto com docentes como com alunos em diferentes níveis de ensino, alcançando resultados positivos (MORESCO; BEHAR, 2006; SANTIAGO; LIMA, 2013).

A plataforma construída mostrou vantagens uma vez que pode armazenar uma extensa quantidade de informações sem custos, carregando como característica a facilidade de produção e manipulação, como encontrado nos estudos de Franco (2005), o que the atribui grande capacidade pedagógica e formativa, desde que empregados com fins educacionais.

Acentua-se que no blog elaborado nesta pesquisa estas vias puderam ser multiplicadas pelo intercruzamento de linguagens, que ultrapassaram a leitura e a escrita, sobretudo pela presença dos vídeos, imagens e músicas. Na seção do xaxado, por exemplo, foram disponibilizadas imagens históricas relativas ao cangaço nordestino, movimento que se confunde com a história dessa manifestação, desenhos e ilustrações de passos que podem ser realizados nas coreografias, vídeos e documentários reunindo um corpo teórico sobre 0 tema, bem como, exemplos de apresentações desenvolvidas em escolas, além de músicas que o professor poderia utilizar em suas aulas. Como salienta Moresco e Behar (2006, p. 3) "desta forma, são ampliadas as possibilidades de um diálogo mais autêntico e profundo com outras formas de saber, outros pontos de vista favorecendo a interdisciplinaridade, ajudando a construir redes sociais e redes de saberes". 
A exploração da linguagem audiovisual como apoio ao professor denota outras maneiras de mobilização do conhecimento, proporcionando uma percepção acima da reflexão, promovendo respostas aliadas com a afetividade e a emoção (FERRÉS, 1996). Em relação a esse tema, os professores se posicionaram:

[...] eu achei alguns vídeos excelentes! Ainda mais porque tinha, assim, de um grupo profissional... e um grupo escolar... achei assim fantástico... e com coisas bonitas, coisas bem feitinhas... nada de super produção [...] eu achei assim muito legal pois mostra que é possível fazer. (Professor 2).

O que me chamou mais atenção foi a catira, porque você colocou os vídeos, e isso ajudou bastante, para eu poder pegar e mostrar para os meus alunos, daquela forma que você colocou acho que é bem legal, até porque tinha... adulto fazendo, mas tinha criança também, que são pessoas da idade deles trabalhando... é isso. (Professor 5).

Com relação às dificuldades para acessar o blog, todo o grupo informou que não enfrentou problemas, uma vez que, já estavam ambientados com o computador e com a internet.

Não, não tive dificuldades, é um blog que como eu falei pra você [...] é fácil de entrar, é fácil de você achar o que você tá procurando, tudo bem organizado, com boa visualização. Então, eu achei assim, muito fácil de trabalhar com ele, não tive dificuldade nenhuma no acesso ao blog. (Professor 2).

Apesar da literatura apontar todas as dificuldades que os professores possuem em se apropriar das TIC de modo significativo e contextualizado no ensino dos conteúdos (MASETTO, 2006; OLIVEIRA, 2012), esta investigação suscitou algumas possibilidades, destacando que ferramentas mais simples da internet, como o blog, já podem ser implementadas em ambientes educacionais sem maiores receios, fortalecendo a proposta do estudo.

\subsubsection{Blog como material didático para o professor}

A ausência de materiais didáticos de qualidade para os professores de Educação Física é uma das grandes dificuldades apresentadas pelos profissionais da área. Darido et al. (2010) e Diniz e Darido (2012) apontam que ferramentas como livros didáticos são escassas na Educação Física, limitando ainda mais o trabalho do professor.

Maciel, Silva e Bazzo (2007) subscrevem esta carência de materiais complementares para os professores, sugerindo o uso das tecnologias como possibilidades viáveis para suprir esta deficiência. Neste escopo, as tecnologias podem ressignificar a concepção de material didático.

Mesmo os dois professores que já possuíam algumas experiências com a dança, principalmente devido à abrangência do conteúdo, pontuaram a necessidade de materiais didáticos complementares, destacando o blog como uma alternativa viável em seu discurso.

Então... é um site aonde eu vou procurar mais vezes, né?... Porque ai fica fácil... é muito fácil para mim buscar as informações no seu blog... principalmente porque tá tudo no mesmo lugar, arrumadinho.... pronto para usar....ai eu vou lá e busco, é mais rápido! (Professor 5).

Eu gostei do blog, [...] fica fácil montar a aula com o material que tem lá, ficou bastante pedagógico, usei bastante nessa aula que eu fiz, porque muita coisa que não tem no caderno dos alunos, o blog acabou acrescentando e dando um aprofundamento. (Professor 6). 
Entretanto, apesar desses olhares positivos, um dos professores acentuou que existe preconceito com relação à utilização de materiais didáticos diversos na Educação Física, como se isso diminuísse a capacidade do docente durante as aulas, o que apesar de ser um equívoco, é entendido como um obstáculo para a inserção de diferentes recursos nas aulas desta disciplina.

Concorda-se com Sacristán (2000, p. 155) quando o autor afirma que "o professor pode utilizar quantos recursos sentir necessários para auxiliá-lo [...]" a fim de complementar e dar sentidos diversos a sua atuação formativa. Os professores não devem se sentir diminuídos por utilizarem materiais didáticos durante a sua atuação docente, pois usufruir desta estratégia pode enriquecer ainda mais o ambiente de aprendizagem, diversificando sua prática, metodologias empregadas, atividades oferecidas, entre outros aspectos.

Pode-se, afirmar, portanto, que há necessidade de disponibilizar materiais didáticos que reúnam um corpo de conhecimento diversificado, oferecendo textos complementares, curiosidades, vídeos, entre outros elementos, que possam proporcionar aos professores maiores ferramentas para abordar as danças folclóricas e outros conteúdos, procurando superar a resistência que a área pode apresentar.

\subsubsection{Blog como possibilidade de formação continuada}

A utilização das TIC e em específico do blog como estratégias de apoio à formação continuada para os professores de Educação Física, também emergiu como uma possibilidade durante este estudo. Empregar estas tecnologias como uma base para a atuação docente pode proporcionar avanços na prática pedagógica, ressignificando conteúdos e ampliando o acesso a temas que possuem pouco espaço na escola.

Concorda-se com Scherer (2005) que a formação e a educação não ocorrem apenas em espaços presenciais, e assim, os ambientes virtuais podem preencher lacunas da formação inicial. Alguns estudos já empregaram as TIC como estratégias de formação continuada (MOREIRA; LOREIRO, 2009; BARCELOS, 2011) em diferentes áreas, ressaltando a relevância que as tecnologias vêm ocupando no campo educacional como uma via de acesso ao conhecimento em larga escala e com baixos custos.

A formação continuada é necessária em praticamente todas as áreas, e o professor não deve se eximir deste processo procurando ressignificar a sua prática explorando os diferentes conteúdos da cultura corporal nas aulas de Educação Física. Entende-se que o blog educacional de danças folclóricas pode atuar como uma possibilidade virtual de apoio à formação continuada, já que a plataforma disponibilizou um conteúdo consistente acerca das cinco manifestações folclóricas propostas como conteúdo curricular oficial da área: "O blog ajuda bastante... é importante para estudar... é bacana, é totalmente diferente de ficar guardando um monte de papel... que você vai procurar e depois não acha." (Professor 1).

Salienta-se, portanto, que este ambiente pode ser enriquecido ainda mais e proporcionar maiores oportunidades de formação continuada expandindo os temas abordados, e oferecendo conteúdos diversificados e interativos para os professores. As demandas atuais referentes à formação inicial e continuada são outras, e necessitam passar por mudanças substanciais nos currículos e metodologias, principalmente no sentido multidisciplinar e na acelerada obsolescência do conhecimento (BELLONI, 2001). 


\subsubsection{As danças folclóricas como conteúdo da Educação Física escolar}

Um fator bastante presente na fala dos professores durante 0 estudo referiu-se à relevância do folclore e, em específico, das danças folclóricas como conteúdos pertinentes para serem ensinados nas aulas de Educação Física: "As danças eram muito o foco, que dá para trabalhar dentro das escolas na parte de folclore mesmo né? Porque dá para você trabalhar bastante com a parte de folclore [...]." (Professor 4).

As danças folclóricas se constituem em uma temática que gradativamente conquistou seu espaço em planos educacionais, e que, atualmente integra as Propostas Curriculares Estaduais de diversos estados brasileiros como de Pernambuco (2008) e do Paraná (2008), além de outros. Ademais, o folclore é apontado em alguns estudos como fator expressivo da cultura que precisa ser ensinado nas escolas de modo planejado (IZUMI; MARTINS JÚNIOR, 2006; TOLEDO, 2011).

Entretanto, este conteúdo ainda não faz parte da realidade das escolas públicas. Desta forma, as danças folclóricas necessitam de maiores oportunidades para serem inseridas na Educação Física, pois sua abordagem nesta disciplina pode levar o aluno a refletir sobre 0 conhecimento de sua cultura e história.

Para os professores participantes as danças folclóricas já fizeram parte do contexto educacional de modo mais significativo, apontando que, na atualidade esta tradição vem se perdendo. Este quadro parece preocupante, uma vez que os alunos pouco conhecem sobre estas manifestações e a escola tem deixado de explorá-las.

\subsubsection{Dificuldades e limitações do estudo}

\subsubsection{Participação docente e as dificuldades com o tratamento da dança}

Selecionar os participantes foi um dos problemas iniciais enfrentado durante o estudo, uma vez que, apesar das escolas se mostrarem receptivas, no momento em que as fases da pesquisa eram esclarecidas havia resistência por parte dos professores de Educação Física.

Desta forma, algumas instituições apesar do interesse inicial da equipe gestora em colaborar com a pesquisa não puderam, uma vez que os professores não aceitaram participar, principalmente por receio da etapa de implementação das aulas.

A minha formação, foi uma formação voltada exclusivamente para o esporte, a Educação Física, ela tinha como parâmetro o esporte. Além disso, em primeiro lugar, nós não temos material, em segundo lugar nos não temos espaço que a gente possa realmente elaborar uma aula de dança, não temos sala preparada. Então, fica muito difícil [...]. (Professor 3).

Estas justificativas corroboram com outras pesquisas que investigaram junto aos professores os motivos que os impediam de inserir a dança na escola (MARQUES, 1997; CAPRI; FINK, 2009). Brasileiro (2008) evidenciou que apesar de motivos como estes serem comumente apontados, a ausência de conhecimento sobre este conteúdo parece um dos principais impedimentos pedagógicos. Como salienta Neira (2011) dificilmente um professor ensinará um conhecimento se ele não possuir certa compreensão de suas possibilidades educacionais, e assim, a dança pode perder espaço na escola. 
"Professores de educação física não se veem capacitados para tratar de um conhecimento que foi desenvolvido em uma ou duas disciplinas em seus processos de formação" (BRASILEIRO, 2008, p. 525). Todavia, a autora reporta que historicamente conquistaram-se melhorias significativas, e que a situação vem melhorando, como por exemplo, o número de disciplinas que tratam desse conteúdo ter aumentado nos últimos anos.

\subsubsection{Estrutura da escola e as TIC}

A ausência de salas de informática com condições de uso, rádios com entrada USB, datashow em funcionamento e espaços adequados para prática de atividades também se constituíram em elementos que interferiram no estudo, principalmente nas escolas em que foram implementadas as aulas. Assim, o planejamento dos professores teve que ser adaptado à realidade das instituições de ensino.

Esta conjuntura denota que apesar da utilização das tecnologias, das mídias eletrônicas e da internet serem propostas como ferramentas pedagógicas há mais de quinze anos, a escola pública e os currículos não conseguiram acompanhar esse ritmo: "Então a gente até tem alguns recursos, o problema é que é número reduzido e de vez em quando não funciona [...]." (Professor 6).

Apesar das instituições participantes possuírem parceria com o Projeto Acessa Escola ${ }^{5}$, apenas uma delas está com este espaço em condições de uso. 0 Acessa Escola é um programa do Governo do estado de São Paulo, desenvolvido em conjunto pelas Secretarias de Estado da Educação e de Gestão Pública, com a coordenação da Fundação para o Desenvolvimento da Educação (FDE). Em duas escolas esta sala ainda não estava funcionando por problemas como falta de recursos financeiros e de espaços adequados, bem como, por problemas na estrutura elétrica.

As tecnologias ainda possuem dificuldades para adentrar os muros da escola, considerando que apesar da existência de projetos para estimular a melhoria das salas de informática, e consequentemente o acesso à internet, as instituições públicas ainda esbarram em alguns empecilhos. Acentua-se, no entanto, que as ferramentas tecnológicas não podem ser consideradas como a solução para todos os problemas escolares, tendo em vista que, os avanços no campo educacional dependem de muitos fatores.

\subsubsection{Condições do trabalho docente: implicações sobre e a dança e as TIC}

As condições de trabalho foram constantemente apontadas como problemas durante 0 estudo. Um dos professores participantes afirmou o seguinte sobre ensinar a dança na escola:

E aí, você até vai na internet para pesquisar as coisas e tal... mas as condições de trabalho que você tem são muito difíceis, e assim, geralmente você só passa uma pesquisa e pronto. [...] Só esse ano eu estou com 32 aulas, no ano passado eu tinha 46. [...] Mas, volto a reafirmar que é muito difícil [...]. (Professor 1).

Apesar da grande capacidade interativa que o blog possui (KOMESU, 2005; CASTRO FILHO, 2008), esse viés foi prejudicado ao longo do estudo por fatores que envolviam as condições do trabalho docente. A interatividade poderia permitir trocas de experiências entre 
todos os visitantes da plataforma, bem como criar uma rede virtual entre os professores de Educação Física do estado por meio de troca de experiências e saberes.

Apesar dos participantes já apresentarem experiências com blogs diversos, eles assumiram que normalmente não interagem principalmente pela falta de tempo, o que pode ser observado no discurso dos participantes:

Não interajo, eu só pego as informações que são úteis para mim, eu sei que é um pouco egoísta... mas eu só pego o que preciso e já saio, num dá tempo" [...]. Não registrei as aulas no blog, porque não organizei meu tempo para isso. Depois que saio da escola é muito difícil, pois ainda tenho que organizar as próximas aulas e fazer... fazer... as minhas coisas pessoais também (Professor 1).

O processo de precarização do trabalho docente já tem sido estudado em diversas pesquisas (FERNANDES, 2010; OLIVEIRA, 2008) apontando os efeitos que ele pode causar na atuação dos professores e consequentemente na aprendizagem dos alunos. Contudo, compreender o panorama que se tem na atualidade acerca das políticas que permeiam este tema requer uma análise mais profunda, que foge do escopo dessa pesquisa.

Especificamente para a Educação Física, estes delineamentos podem ser mais aprofundados, pois a área é ainda mais desvalorizada no contexto escolar. Desta forma, os docentes se veem encurralados em meio aos problemas da carreira somados aos agravantes desse campo.

[...] a estrutura da escola, é o que mais impede ensinar a dança, esse que é o grande problema. E não é só a estrutura física, a forma como a escola está estruturada, impede que trabalhos diferentes sejam realizados, tudo de novo na escola é difícil de ser colocado em prática! [...] A coisa mais fácil é você ficar quietinho na sua aula... sem pedir nada... e não dando trabalho para ninguém. (Professor 3).

Este enredo tecido pelo professor ilustra o sentimento de desvalorização arraigado de sua profissão, panorama que impede, muitas vezes, os docentes de se engajarem em projetos que favoreçam a entrada da dança de forma mais significativa nas aulas de Educação Física.

Apesar dessas dificuldades, salienta-se que a interatividade pode ser compreendida como uma das principais vantagens do blog, assim, seria interessante que os professores pudessem incluir essas ferramentas digitais em propostas de formação continuada, bem como, de maneira integrativa ao fazer pedagógico. Isso poderia ser desenvolvido, por exemplo, durante as aulas de forma conjunta com os alunos, ou ainda, nos momentos de encontro coletivo da escola. Como os próprios professores salientaram durante a pesquisa, seria mais uma alternativa didática viabilizada: "O blog é muito interessante... muito assim... que dá para ser utilizado em aula, pois é uma coisa bem dinâmica, é uma coisa para se usar em sala de aula, e não é só para você, é para os alunos [...]." (Professor 4).

Em um blog sempre se espera a resposta do outro em relação ao tema tratado (KOMESU, 2005), de forma que o diálogo não seja unidirecional e possa ser ampliado e ressignificado a partir de múltiplos olhares de seus visitantes.

\section{CONSIDERAÇÕES FINAIS}

Com o objetivo de elaborar e avaliar um material didático de danças folclóricas, publicado por meio de um blog educacional, esta pesquisa pode reunir um corpo de conhecimento 
significativo sobre este tema e investigar junto a professores da rede pública do Estado de São Paulo quais as principais possibilidades pedagógicas de uma proposta com o uso das TIC para a disponibilização de materiais didáticos.

A partir do conteúdo proposto pelo caderno do professor do currículo de Educação Física do Estado de São Paulo para o sétimo ano do ensino fundamental foi possível avançar no tema das danças folclóricas e produzir um material de apoio com mais subsídios didáticos para favorecer a inserção deste conteúdo na escola.

Analisar os dados obtidos com as entrevistas evidenciou o quanto os professores necessitam de materiais didáticos complementares para aprimorar seus conhecimentos e refletir sobre a sua prática pedagógica. Ademais, trouxe mais uma ferramenta para tratar as danças folclóricas junto aos estudantes de forma sistematizada, contribuindo para que eles não sejam privados de conhecer este conteúdo.

Deste modo, apesar das dificuldades encontradas durante o desenvolvimento da pesquisa, como as questões estruturais da escola e as condições do trabalho docente, por exemplo, o blog educacional se apresentou como uma alternativa pedagógica viável para 0 professor no processo de ensino e aprendizagem das danças folclóricas.

Neste sentido, este trabalho suscitou contribuições relevantes para a área Educação Física escolar e para a inserção das danças folclóricas como um conteúdo regular. Os professores participantes puderam se aproximar desta temática e explorar durante sua prática pedagógica conhecimentos acerca deste conteúdo, que até então, tinham sido pouco explorados ao longo de suas experiências.

\section{REFERÊNCIAS}

BARCELOS, Gilmara Teixeira. Tecnologias na prática docente de professores de

Matemática: formação continuada com apoio de uma rede social na internet. 2011. $332 \mathrm{f}$. Tese (Doutorado em Informática na Educação) - Faculdade de Educação, Universidade Federal do Rio Grande do Sul, Porto Alegre, 2011.

BARDIN, Laurence. Análise de conteúdo. Tradução de L. A. R.; A. Pinheiro. São Paulo: Edições 70, 2011.

BELLONI, Maria Luiza. Educação à distância. 2. ed. Campinas: Autores Associados, 2001.

BRASILEIRO, Lívia Tenório. O conhecimento no currículo escolar: o conteúdo dança em aulas de educação física na perspectiva crítica. Movimento, Porto Alegre, v. 8, n. 3, p. 5-18, set./dez. 2002.

BRASILEIRO, Lívia Tenório. O ensino da dança na educação física: formação e intervenção pedagógica em discussão. Motriz, Rio Claro, v. 14, n. 4, p. 519-528, out./dez. 2008.

CAPRI, Fabíola Schiebelbein; FINCK, Sílvia Christina Madrid. A dança no contexto da educação física: uma análise da prática de ensino no processo de formação docente. EF deportes, Buenos Aires, v. 13, n. 128, 2009. Disponível em: <http://www.efdeportes.com/efd128/a-danca-nocontexto-da-educacao-fisica.htm>. Acesso em: 15 jan. 2014. 
CASTRO FILHO, José Aires de. et al. Linguagens midiáticas e comunicação em EaD. Em Aberto, Brasília, v. 21, n. 79, p. 47-58, 2008.

DARIDO, Suraya Cristina. et al. Livro didático na educação física escolar: considerações iniciais. Motriz, Rio Claro, v. 16, n. 2, p. 450-457, 2010.

DARIDO, Suraya Cristina; SOUZA JÚNIOR, Osmar Moreira de. Para ensinar educação física: possibilidades de intervenção na escola. Campinas: Papirus, 2007.

DINIZ, Irlla Karla dos Santos; DARIDO, Suraya Cristina. Livro didático: uma ferramenta possível de trabalho com a dança na Educação Física Escolar. Motriz, Rio Claro, v. 18, p. 176-185, jan./ mar. 2012.

EHRENBERG, Monica Caldas. A dança como conhecimento a ser tratado pela educação física escolar: aproximações entre formação e atuação profissional. 2003. 153f. Dissertação (Mestrado em Educação Física) - Faculdade de Educação Física, Universidade Estadual de Campinas, Campinas, 2003.

FERNANDES, Hélio Clemente. 0 trabalho docente: pauperização, precarização e proletarização. 2010. 195f. Dissertação (Mestrado em Educação) - Universidade Estadual do Oeste do Paraná, Cascavel, 2010.

FERRÉS, Joan. Vídeo e educação. Tradução de Juan Acuña Lorens. 2. ed. Porto Alegre: [s.n.], 1996.

FRANCO, Maria de Fátima. Blog Educacional: ambiente de interação e escrita Colaborativa. In: SIMPÓSIO BRASILEIRO DE INFORMÁTICA NA EDUCAÇÃO, 16. 2005. Anais... Disponível em: <http://www.br-ie.org/pub/index.php/sbie/issue/view/25>. Acesso em: 20 nov. 2013.

FREIRE, João Batista; SCAGLIA, Alcides José. Educação como prática corporal. São Paulo: Scipione, 2003.

GIL, Antônio Carlos. Como elaborar projetos de pesquisa. 4. ed. São Paulo: Atlas, 2008.

GONZÁLEZ, Fernando Jaime. Projeto Curricular em Educação Física: o esporte como conteúdo escolar. In: REZER, Ricardo (Org). O fenômeno esportivo: ensaio crítico-reflexivo. Chapecó: Argos, 2006. p. 69-109.

IZUMI, Carolina Miyuki; MARTINS JUNIOR, Joaquim. A relevância do folclore nas escolas municipais: um estudo sobre a dança folclórica. Iniciação Científica Cesumar, Maringá, v. 8, n. 2, p. 111-117, 2007.

KLEINUBING, Neusa Dendena.; SARAIVA, Maria do Carmo. Educação Física escolar e dança: percepções de professores no ensino fundamental. Movimento, Porto Alegre, v. 15, n. 4, p. 193-214, out./dez. 2009. Disponível em: <http://www.seer.ufrgs.br/Movimento/article/view/4610>. Acesso em: 18 jan. 2015.

KOMESU, Fabiana Cristina. Entre o público e privado: um jogo enunciativo na constituição do escrevente de Blogs da internet. 2005. 261f. Tese (Doutorado em Linguística) - Instituto de Estudos da Linguagem, Universidade Estadual de Campinas, Campinas.

KUNZ, Elenor. Educação física: ensino e mudanças. ljuí: Unijuí, 1991.

LÜDKE, Menga; ANDRÉ, Marli. Pesquisa em educação: abordagens qualitativas. São Paulo: EPU, 1986. 
MACIEL, Nilceia Aparecida Pinheiro; SILVA, Eloiza Aparecida Avila de Matos; BAZZO, Walter Antônio. Refletindo acerca da ciência, tecnologias em sociedade: enfocando o ensino médio.

Revista Iberoamerica de Educación, Madrid, n. 44, p. 147-165, maio 2007.

MARQUES, Daniela Vieira Aquino; MÜLLER, Fernanda. Experiências com blog na pesquisa e na formação inicial de professoras de educação infantil. Educação Temática Digital, Campinas, v. 14, p. 43-61, jan./jun. 2012.

MARQUES, Isabel Azevedo. Dançando na escola. Motriz, Rio Claro, v. 3, n. 1, p. 20-27, 1997.

MASETTO, Marcos. T. Mediação pedagógica e o uso da tecnologia. In: MORAN, José Manoel.; MASETTO, Marcos Tarcísio; BEHRENS, Marilda Aparecida. Novas tecnologias e mediação pedagógica. 12. ed. Campinas: Papirus, 2006. p. 133-173.

MOREIRA, António; LOUREIRO, Maria José. Enquadramento das TIC na formação contínua de professores. In: COSTA, Fernando. (Coord.). Competências TIC: estudo de implementação. Lisboa: Gabinete de Estatística e Planejamento da Educação, 2009. v. 2, p. 117-160.

MORESCO, Silvia Ferreto da Silva; BEHAR, Patricia Alejandra. Blogs para a aprendizagem de física e química. RENOTE - Revista Novas Tecnologias na Educação, Porto Alegre, v. 4, p. 1-9, jul. 2006. Disponível em: <http://seer.ufrgs.br/renote/article/view/14121/7996>. Acesso em: 20 set. 2013.

NEIRA, Marcos. A proposta curricular do Estado de São Paulo na perspectiva dos saberes docentes. Revista Brasileira de Educação Física e Esporte, São Paulo, v. 25, n. 6, p. 23-27, 2011.

OLIVEIRA, Dalila Andrade. O trabalho docente na América Latina: identidade e

profissionalização. Retratos da Escola, Brasília, v. 2, n. 2/3, p. 29-39, jan./dez. 2008.

OLIVEIRA, José Sávio de. Professor X TICS: dificuldades ou comodismo? Diálogos

Educacionais em Revista, Campo Grande, v. 3, n. 1, p. 99-111, jun. 2012.

PARANÁ. Secretaria de Estado da Educação. Diretrizes curriculares da

educação básica: educação física. Curitiba, 2008.

PERNAMBUCO. Secretaria de Educação. Orientações teórico-metodológicas: ensino fundamental, educação física. Recife, 2008.

SACRISTÁN, José Gimeno. 0 currículo: uma reflexão sobre a prática. 3. ed. Tradução de E. F. F. Rosa. Porto Alegre: Artmed, 2000.

SANTIAGO, Maria Francilene Câmara; LIMA, Rommel Wladimir de. Blog: uma ferramenta de aprendizagem no ensino médio inovador. In: CONGRESSO BRASILEIRO DE INFORMÁTICA NA EDUCAÇÃO, 2. 2013. WORKSHOP DE INFORMÁTICA NA ESCOLA, 19. 2013.. Anais..., Campinas, 2013. p. 80-89.

SÃO PAULO. Secretaria da Educação. Caderno do professor: educação física, ensino fundamental- 6 a série. São Paulo: SEE, 2009.

SÃO PAULO. Secretaria da Educação. Currículo do Estado de São Paulo: Linguagens, códigos e suas tecnologias. 2. ed. São Paulo, 2011.

SCHERER, Suely. Uma estética possível para a educação bimodal: aprendizagem e comunicação em ambientes presenciais e virtuais uma experiência em estatística aplicada à 
educação. 2005. 241f. Tese (Doutorado em Educação) - Pontifícia Universidade Católica de São Paulo, São Paulo, 2005.

SILVA, Luciana Maria. 0 ensino da capoeira na Educação Física escolar: blog como apoio pedagógico. 2012. 175f. Dissertação (Mestrado em Desenvolvimento Humano e Tecnologias) - Instituto de Biociências, Universidade Estadual Paulista, Rio Claro, 2012.

TOLEDO, Eliana de. O folclore na escola: um esquecido, porém precioso, conteúdo da Educação Física. In: MOREIRA, E. C.; PEREIRA, R. S. Educação Física escolar: desafios e propostas 2. 2. ed. São Paulo: Fontoura, 2011, p. 65-92. financiamento desta pesquisa. 